Electronic Physician (ISSN: 2008-5842)

http://www.ephysician.ir

February 2016, Volume: 8, Issue: 2, Pages: 1904-1910, DOI: http://dx.doi.org/10.19082/1904

\title{
The correlation between organizational justice and trust among employees of rehabilitation clinics in hospitals of Ahvaz, Iran
}

\author{
Farzad Faraji Khiavi ${ }^{1}$, Kamal Shakhi ${ }^{2}$, Roohallah Dehghani ${ }^{3}$, Mansour Zahiri ${ }^{1}$
}

${ }^{1}$ Ph.D. of Health Services Administration, Assistant Professor, Social Determents of Health Research Center, Department of Health Services Management, School of Health, Ahvaz Jundishapur University of Medical Sciences, Ahvaz, Iran

2 M.Sc. in Rehabilitation Administration, Social Determents of Health Research Center, Ahvaz Jundishapur University of Medical Sciences, Ahvaz, Iran

${ }^{3}$ M.Sc. in Business Administration, Social Determents of Health Research Center, Ahvaz Jundishapur University of Medical Sciences, Ahvaz, Iran

\section{Type of article: Original}

\begin{abstract}
Introduction: Organizational justice is an intricate concept that refers to fair and ethical conduct of individuals within organizations. No research has been conducted on the variables associated with organizational justice in rehabilitation clinics. Thus, the aim of this research was to determine the correlation between organizational justice and organizational trust among the employees of rehabilitation clinics in hospitals of Ahvaz, Iran.

Methods: This was a cross-sectional research, and it was conducted on 140 rehabilitation staff members of hospital clinics in Ahvaz. The data were gathered using organizational justice and trust questionnaires. The data were analyzed using the independent-samples t-test, ANOVA, and Pearson's product-moment correlation SPSS software.

Results: Significant correlations between procedure and interaction justice and organizational trust were identified $(\mathrm{p}<0.001)$. Distributive justice showed small correlation with trust $(\mathrm{r}=0.25, \mathrm{p}<0.021)$. Organizational justice was significantly associated with organizational trust $(\mathrm{r}=0.42, \mathrm{p}<0.001)$. Organizational justice was not significantly related to any demographic variable $(\mathrm{p}>0.05)$.

Conclusion: There was a positive, medium, and significant correlation between organizational justice and trust. It is suggested that rehabilitation clinics' managers develop plans to increase their organizational justice subscales in order to develop organizational trust among their employees.
\end{abstract}

Keywords: organizational justice, organizational trust, rehabilitation clinics, hospital

\section{Introduction}

Organizational justice has attracted much attention as an important concept in organizational psychology (1). The results of the studies indicated that employees' perception of organizational justice affected some variables, including attitude about the job, work quality, performance, efficiency, and coordination in the organization (2-7). Organizational justice refers to fair and ethical conduct of individuals within an organization (8). Justice processes have important roles in an organization, because they are associated with the concepts of organizational commitments, organizational citizenship behavior, job satisfaction, and performance $(9,10)$. Furthermore, the way the organization treats its employees affect their beliefs, feelings, attitudes, and behaviors (11). There are three types pf organizational justice, i.e., 1) distributive justice, which refers to the employees' perception of fairness of the results, allocations, and payments of the organization to the employees; 2) procedural justice, which represents the extent of the fairness of decision-making procedures on results or policies or formal procedures of their allocation;

\section{Corresponding author:}

Assistant Professor Dr. Mansour Zahiri, Social Determents of Health Research Center, Department of Health Services Administration, School of Health, Ahvaz Jundishapur University of Medical Sciences, Ahvaz, Iran. Tel: +98.6133738269, Fax: +98.6133738282, Email: man_zahiri@yahoo.co.uk Received: September 22, 2015, Accepted: January 10, 2016, Published: February 2016 iThenticate screening: January 10, 2016, English editing: February 02, 2016, Quality control: February 06,2016 (C) 2016 The Authors. This is an open access article under the terms of the Creative Commons Attribution-NonCommercialNoDerivs License, which permits use and distribution in any medium, provided the original work is properly cited, the use is non-commercial and no modifications or adaptations are made. 
and 3) interactional justice, which refers to the fairness of behavior of decision makers in an organization to the employees, the respect of supervisors to subordinates, and interpersonal relationships (12-16). Many research in organizational justice have focused on the distribution of payments and bonuses related to the job, as derived from Adams' theory (17). The importance of organizational justice lies in the fact that if the employees feel inequality, they turn to be a potential source of dissatisfaction within the organization that would leave irreparable consequences (18). Organizational justice results in different consequences, among which a very significant one is organizational trust, which has been the focus of attention in recent years (19). It is believed that trust of employees in a certain level affects their trust in another one. The trust of employees in their supervisor actually affects their trust in the organization, and, on the contrary, any distrust of supervisors and other officials would lead to certain negative behaviors (20). The social exchange model defines the concept of trust as a desire of people to make themselves vulnerable to the reactions of others and put them in control of consequences (21). According to Moorman, trust, as a key element in new mutual relationships, means having confidence in the intentions and actions of others. Intricacy and lack of confidence in nature of contemporary business as well as the volume of mutual cooperation make the efficiency of work relationships more complicated. In these conditions, preserving efficient partnerships is possible only when the relationships are transparent, and this comes solely from mutual trust and confidence (22). Trust is predictive of positive performance within inter-organizational relationships (23). Smith et al. maintained that trust is an important fundamental element that predicts the cooperation level within and between organizations (24). Trust is associated with several attitude consequences, particularly organizational commitment and job satisfaction (25). Organizational trust is a factor capable of increasing trust in the supervisor and the organization (26). It is believed that when the distribution of organizational benefits and consequences is deemed to be fair, a higher level of trust would probably emerge (27). The results of Floger's study demonstrated that the employees who believe their managers have evaluated them on fair practices are interested in considering their trust positively (28). The results of the previous studies show that the perception of organizational justice affects the organizational support and the organizational trust. DeConinck believed that when the employees are treated fairly concerning the grant of bonuses, and prepared with a chance of making comments within the assessment process, and when their managers deal with them in person based on justice and fairness, the level of trust between the supervisor and subordinate, and, accordingly, the organizational trust increases, which would result in positive achievements $(29,30)$. The results of Bahrami's study indicated that employees' perception of organizational justice may affect the trust in the organization and managers (31). Farndale demonstrated that there is a significant, large and positive correlation between organizational justice and trust in managers (32). Also, the results of a study in Iraq indicated that organizational justice affects organizational trust, and the latter is able to predict organizational justice and participation (33).

In the case of experiencing justice and fairness in organizational consequences, processes, and interactions, employees in an organization would see more safety and have more interest in having trust in the supervisor and the organization which may bring about increases in job satisfaction, organizational commitment, and performance (26). Given the significance of this issue and since no research has been conducted on the correlation between organizational justice and organizational trust in rehabilitation clinics, the results of this study seem beneficial for managers in Iran's health sector. Therefore, the aim of this research was to determine the correlation between organizational justice and organizational trust among the employees of rehabilitation clinics in the hospitals of Ahvaz.

\section{Material and Methods}

\subsection{Research design}

This was a cross-sectional research project, and it was conducted on the rehabilitation staff of the hospital clinics in Ahvaz. All of the employees of the rehabilitation clinics in the hospitals Ahvaz made up the statistical population of this research. Rehabilitation clinics were included in the study if they had at least three permanent employees with more than one year of work experience. Sampling was not conducted due to the limited statistical population $(\mathrm{n}=$ 140). The employees included in the study were from various departments, including physiotherapy, occupational therapy, speech therapy, audiology, psychology, and social work, from eight public hospitals, five private hospitals, and two rehabilitation clinics associated with universities.

\subsection{Materials}

Three questionnaires were used to gather information, i.e., 1) a demographic questionnaire that consisted of several questions on age, gender, occupational experience, education, and job; 2) an organizational justice questionnaire, which was comprised of 20 questions that examined the dimensions of organizational justice, i.e., distributive 
justice, procedural justice, and interactional justice, based on a 5-degree Likert scale of very high, high, medium, low, and very low; the validity of the organizational justice questionnaire had already been confirmed by opinion leaders of management in Alipour's study, and its reliability was proved by calculating the Cronbach's Alpha as approximately $0.84(34) ; 3$ ) an organizational trust questionnaire that included two parts, i.e., trust in the organization and trust in supervisors. The first part had eight questions derived from the studies of Moorman, Blakely, and Niehoff, and it assessed the existence of trust within an organization based on five degrees, i.e., strongly disagree to strongly agree. The Cronbach's alpha for this questionnaire was calculated as 0.66 . Its second part had three questions and was prepared based on the studies of Hartoog and Kopman. The response scale for this questionnaire was five degrees, and its Cronbach's alpha was 0.87 (26). The Cronbach's alpha values in this study for the organizational justice, organizational trust, and trust in supervisor questionnaires were calculated as more than 0.80 .

\subsection{Data analysis}

Descriptive statistics and central statistical indices, such as mean and standard deviation, were used to describe the findings. The distribution of the data was normal. The independent-samples t-test, ANOVA, and Pearson correlation in SPSS16 were used to determine the correlations between the variables.

\section{Results}

\subsection{Socio-Demographic Characteristics of Participants}

The participants completed 114 questionnaires out of the 140 that were distributed, providing a response level of $81 \%$. Among the respondents, 65 were females $(57.02 \%)$ and 49 were males $(42.98 \%)$. The highest frequency of respondents was allocated to the age group of 30-40 with 56.14\% (64). The age groups under 30, 40-50, and over 50 were $31(27.19 \%), 17(14.19 \%)$, and $2(1.76 \%)$, respectively. There were 76 married respondents $(66.7 \%)$ and 38 single respondents (33.3\%). Sixty participants (52.63\%) had a BA degree, $43(37.71 \%)$ had an MA degree, and 11 $(9.66 \%)$ had a Ph.D. degree. Most respondents had less than 5 years of work experience $(37.72 \%)$ and only 5 respondents had work experience of more than 20 years $(4.38 \%)$. Table 1 provides the sociodemographic characteristics of the participants, as well as their mean organizational trust and justice scores.

Table 1. Socio-Demographic characteristics of the participants

\begin{tabular}{|c|c|c|c|c|c|}
\hline \multirow[t]{2}{*}{ Variables } & \multirow[t]{2}{*}{ Categories } & \multirow[t]{2}{*}{$\mathrm{n}(\%)$} & Organizational Trust & Organizational Justice & \multirow[t]{2}{*}{$\mathrm{p}$-value } \\
\hline & & & Mean \pm SD & Mean \pm SD & \\
\hline \multirow[t]{2}{*}{ Gender } & Male & $49(42.98)$ & $3.24 \pm 0.65$ & $2.94 \pm 0.76$ & \multirow[t]{2}{*}{$>0.05$} \\
\hline & Female & $65(57.02)$ & $3.49 \pm 0.53$ & $2.98 \pm 0.69$ & \\
\hline \multirow[t]{4}{*}{ Age (year) } & $<30$ & $31(27.19)$ & $3.33 \pm 0.69$ & $3.04 \pm 0.74$ & \multirow[t]{4}{*}{$>0.05$} \\
\hline & $30-40$ & $64(56.14)$ & $3.41 \pm 0.56$ & $2.76 \pm 0.79$ & \\
\hline & $40-50$ & $17(14.91)$ & $3.59 \pm 0.47$ & $3.06 \pm 0.49$ & \\
\hline & $>50$ & $2(1.76)$ & $3.11 \pm 0.24$ & $3.24 \pm 0.42$ & \\
\hline \multirow[t]{3}{*}{ Education } & B.Sc. & $60(52.63)$ & $3.47 \pm 0.53$ & $2.79 \pm 0.71$ & \multirow[t]{3}{*}{$>0.05$} \\
\hline & M.Sc. & $43(37.71)$ & $3.58 \pm 0.17$ & $2.31 \pm 0.86$ & \\
\hline & Ph.D. & $11(9.66)$ & $3.09 \pm 0.94$ & $3.02 \pm 0.92$ & \\
\hline \multirow[t]{2}{*}{ Marital status } & Married & $76(66.67)$ & $3.37 \pm 0.64$ & $2.99 \pm 0.77$ & \multirow[t]{2}{*}{$>0.05$} \\
\hline & Single & $38(33.33)$ & $3.43 \pm 0.48$ & $2.88 \pm 0.72$ & \\
\hline \multirow{5}{*}{$\begin{array}{l}\text { Work } \\
\text { experience }\end{array}$} & Lower 5 & $43(37.72)$ & $3.38 \pm 0.57$ & $2.83 \pm 0.66$ & \multirow[t]{5}{*}{$>0.05$} \\
\hline & $5-10$ & $15(13.16)$ & $3.64 \pm 0.56$ & $2.75 \pm 0.88$ & \\
\hline & $10-15$ & $39(34.21)$ & $3.23 \pm 0.59$ & $3 \pm 0.77$ & \\
\hline & $15-20$ & $12(10.52)$ & $3.45 \pm 0.46$ & $3.09 \pm 0.73$ & \\
\hline & Upper 20 & $5(4.38)$ & $3.37 \pm 0.47$ & $2.98 \pm 0.54$ & \\
\hline
\end{tabular}

\subsection{Organizational Justice and Trust for different Demographic Variables}

The findings of the study estimated that organizational justice dimension (and its dimensions) among the clinics staff was relatively inappropriate $(2.94 \pm 0.74)$, but the organizational trust dimension was relatively higher $(3.4 \pm$ 0.6). The T-Independent test did not indicate a significant difference between groups with different genders and marital status in terms of organizational justice and trust $(\mathrm{p}>0.05)$. The ANOVA test, also, did not show any meaningful difference between groups with different ages, educational levels, and work experiences in terms of 
organizational justice and trust $(\mathrm{p}>0.05)$. The findings related to demographic variables and the mean difference between organizational justice and trust and demographic variables are shown in Table 1.

\subsection{Correlation between organizational justice and organizational trust}

According to Table 2, trust in organization showed a large correlation with interactional justice, medium correlation with distributive justice and a small correlation with procedural justice. Conversely, trust in supervisor demonstrated medium correlation with procedural and interactional justice, but it had a small meaningful correlation with distributive justice.

Table 2. Pearson Correlation between Organizational Justice and Trust

\begin{tabular}{|l|l|l|l|l|l|}
\hline \multirow{2}{*}{ Organizational Trust } & \multirow{2}{*}{ Statistical Indicators } & \multicolumn{4}{|l|}{ Organizational Justice } \\
\cline { 3 - 6 } & & Distributive & Procedural & Interactional & Total \\
\hline \multirow{2}{*}{ Trust to Organization } & Correlation Coefficient & $0.315^{* *}$ & $0.295^{* *}$ & $0.536^{* *}$ & $0.427^{* *}$ \\
\cline { 2 - 6 } & p-value & 0.009 & 0.006 & $<0.001$ & $<0.001$ \\
\hline \multirow{2}{*}{ Trust to Supervisor } & Correlation Coefficient & $0.179^{*}$ & $0.432^{* *}$ & $0.473^{* *}$ & $0.425^{* *}$ \\
\cline { 2 - 6 } & p-value & 0.04 & $<0.001$ & $<0.001$ & 0.001 \\
\hline \multirow{2}{*}{ Total } & Correlation Coefficient & $0.253^{*}$ & $0.367^{* *}$ & $0.434^{* *}$ & $0.417^{* *}$ \\
\cline { 2 - 6 } & p-value & 0.021 & $<0.001$ & $<0.001$ & $<0.001$ \\
\hline
\end{tabular}

$* \mathrm{p}<0.05 ; * \mathrm{p}<0.01$

\section{Discussion}

\subsection{Socio-Demographic Characteristics}

The findings indicated that employees with different demographic characteristics did not have a significant difference with each other in terms of organizational justice perception. No meaningful difference was observed between men and women's perceptions of organizational justice. The findings of a study by Montazeralfaraj were not consistent with those of this research. He found a significant difference between the perception of organizational justice and the gender of participants, and men felt more justice in organization than women. No meaningful difference was seen between marital status and organizational justice perception, and this was consistent with Montazeralfarj's findings; however, it was inconsistent with the findings of Iranzadeh et al. The latter showed that there was a significant difference between marital status and organizational justice perception $(35,36)$. Yaghoubi et al. demonstrated in their research that there was no meaningful relationship between education and organizational justice perception (36), and this finding was confirmed in our work. The findings of a research project by Elovainio and Manzari Tavakoli suggested that there were meaningful differences between organizational justice perception and the participants' age and work experience. The employees with higher age and work experience, accordingly, understand organizational justice more than those of less age and less work experience $(37,38)$. There was no meaningful relationship between the participants' gender and education and trust in supervisor and organization, which corroborated the findings of Ruder's research (39). Also, no meaningful difference was observed between organizational trust and educational levels, and this was inconsistent with Ruder's findings. Ruder demonstrated in his study that there is a meaningful and inverse correlation between education and trust in supervisor. Another important result of this research was the fact that there was no significant relationship between participants' work experience and organizational trust, which was inconsistent with Ruder's findings (39).

\subsection{Correlation between organizational justice and trust}

There was a positive and significant correlation between all types of organizational justice (distributive, procedural, and interactional justice) and types of trust (trust in supervisor as well as organization). According to the results, there was a positive and significant correlation between distributive justice and trust in supervisor and also trust in organization, which was consistent with the results of research conducted by Ashja et al. (26). Using meta-analysis of organizational justice, Colquitt et al. maintained that there was a unique correlation between interactional and distributive justice and organizational consequences, such as job satisfaction, organizational citizenship behavior, and performance (9). Ruder indicated in his study that there was a significant correlation between procedural justice and dimensions of trust in organization and trust in supervisor, which was consistent with the results of the present study (39). In rehabilitation clinics, it seems the employees are satisfied with the payments, and they see the distribution methods and procedures as fair and just. These results are consistent with those of research findings by AL-Abrrow, who demonstrated that perception of procedural justice is able to predict the trust in supervisor and is probably due to compliance of managers with concentrated decision-making processes and procedures within the 
organization (33). There is, also, another probability that perception of fairness of the processes and procedures would increase the trust in supervisors (33). Moon and et al. showed in analysis of their research that organizational justice in its distributive and procedural dimensions has a positive and significant correlation with organization's payments and expenses (40). The results of this study were consistent also with those of a research by De Cremer who demonstrated that leaders involved in the procedural justice affect the trust in supervisor and organization positively, and the affection-based trust adjusts the correlation of procedural justice (41). There was a positive and significant correlation between interactional justice and trust in organization and supervisor. It seems that the individual dimension of organizational measurements, especially the way supervisors and managers interact with employees, is the most important predictor of trust in organization and supervisor. Seemingly, the behaviors and interactions of managers with employees affect the increase of trust in the organization more than the processes and procedures of decision making of managers as well as the distribution of consequences. The employees' perception about fairness of the behaviors and interactions of supervisors had the most important role in increasing trust in organization. The results of this research were consistent with those of a study by Farndale, who showed that there was a positive, large, and significant correlation between trust in organization and supervisor and organizational justice, especially interactional justice. In other words, organizational justice influences the trust in supervisor (32).

\subsection{Limitations}

These findings are valid just for rehabilitation settings. Because of the limited research population, the findings cannot be generalized to all health subsections in Iran.

\section{Conclusions}

There was a positive, large, and significant correlation between organizational justice and trust (and their dimensions). Organizational justice was a significant incentive in some important organizational behaviors of employees, such as organizational trust, and managers and officials of rehabilitation clinics need to be aware of that. Employees feel better when they perceive justice in their work and organizational setting and see its signs directly and indirectly. In order to establish and promote organizational justice as a factor of increasing of trust in supervisors and the organization, managers may embark on the following activities, i.e., observing justice in distributions and organizational procedures, providing more participation and support of employees in organizational decision making, and making promotions and appointments based on merit.

\section{Acknowledgments:}

This research was funded by the Social Determinants of Health Research Center, Ahvaz Jundishpur University of Medical Sciences, under contract number SDH-9405. The research team appreciates the participation of all the respondents.

\section{Conflict of Interest:}

There is no conflict of interest to be declared.

\section{Authors' contributions:}

All authors contributed to this project and article equally. All authors read and approved the final manuscript.

\section{References}

1) Devasagayam HCH. Organizational citizenship behavior of distributed teams: a study on the mediating effects of organizational justice in software organizations. IJSER. 2013; 4(1): 1-54.

2) Rausch E, Eberlin R, Tatum BC. Organizational justice and decision making: When good intentions are not enough. Management Decision. 2005; 43(7/8): 1040-8. doi: 10.1108/00251740510610035.

3) Devasagayam HC. Organizational citizenship behaviour of distributed teams: A study on the mediating effects of organizational justice in software organizations. International Journal of scientific \& Engineering research. 2013; 4(1): 1-54.

4) Fang R, Lim VK, editors. Collectivism, machiavellianism, perceived organizational justice and organizational citizenship behavior: An empirical study of chinese employees. The second international conference on electronic business; 2002.1-8.

5) Fatimah O, Amiraa A, Halim F. The relationships between organizational justice, organizational citizenship behavior and job satisfaction. Pertanika J Soc Sci \& Hum. 2011; 19: 115-21. 
6) Hedayati S, Faraji O, Mohabbati F, Hamedi S, Emadi V, Sharifi T. Relationship between organizational justice and employees'productivity in hospitals of Zabol city; 2010. 2011: 5(17): 105-18.

7) Nadiri H, Tanova C. An investigation of the role of justice in turnover intentions, job satisfaction, and organizational citizenship behavior in hospitality industry. J Hosp Manage. 2010; 29(1): 33-41. doi: 10.1016/j.ijhm.2009.05.001.

8) Cropanzana R, Bowen DE, Gilliland SW. The management of organizational justice. The Acad Manage Perspect. 2007: 21(4): 34-48. doi: 10.5465/AMP.2007.27895338.

9) Colquitt JA, Conlon DE, Wesson MJ, Porter CO, Ng KY. Justice at the millennium: a meta-analytic review of 25 years of organizational justice research. J Appl Psychol. 2001; 86(3): 425. doi: 10.1037/00219010.86.3.425.

10) Colquitt JA, Noe RA, Jackson CL. Justice in teams: Antecedents and consequences of procedural justice climate. Pers Psychol. 2002; 55(1): 83-109. doi: 10.1111/j.1744-6570.2002.tb00104.

11) van den Bos K. Fundamental research by means of laboratory experiments is essential for a better understanding of organizational justice. J Vocat Behav. 2001; 58(2): 254-9. doi: 10.1006/jvbe.2001.1797.

12) Blakely GL, Andrews MC, Moorman RH. The moderating effects of equity sensitivity on the relationship between organizational justice and organizational citizenship behaviors. J Bus Psychol. 2005; 20(2): 25973. doi: 10.1007/s10869-005-8263-3.

13) Damirchi QV, Talatapeh MB, Darban MZ. Organizational justice and organizational citizenship behavior in Moghan's Agro-Industry Company. International Journal of Management and Social Sciences Research. 2013; 2(3): 68-70.

14) Cropanzano R, Prehar CA, Chen PY. Using social exchange theory to distinguish procedural from interactional justice. Group Organization Management; 2002; 27(3): 324-51. doi: $10.1177 / 1059601102027003002$.

15) Sjahruddin H, Sudiro A. Organizational Justice, Organizational Commitment and Trust in Manager as predictor of Organizational Citizenship Behavior. Interdiciplinary J of contemporary Res Bus. 2013; 4(12): $133-44$.

16) McFarlin DB, Sweeney PD. Research notes. Distributive and procedural justice as predictors of satisfaction with personal and organizational outcomes. Acad Manage J. 1992; 35(3): 626-37. doi: 10.2307/256489.

17) McDowall A, Fletcher C. Employee development: an organizational justice perspective. Personnel Review. 2004; 33(1): 8-29. doi: 10.1108/00483480410510606.

18) Niehoff BP, Moorman RH. Justice as a mediator of the relationship between methods of monitoring and organizational citizenship behavior. Acad Manage J. 1993; 36(3): 527-56. doi: 10.2307/256591.

19) Sarani H, safania A, Razavi S. Evaluation of the impact of dimensions of organizational justice, organizational trust, job satisfaction on male athletes of premier league the iranian futsal. Journal of sport management \& behavior movement. 2014; 10(19): 159-68.

20) Whitener EM, Brodt SE, Korsgaard MA, Werner JM. Managers as initiators of trust: An exchange relationship framework for understanding managerial trustworthy behavior. Acad Manage Rev. 1998; 23(3): 513-30. doi:10.5465/AMR.1998.926624.

21) Meyer JP, Stanley DJ, Herscovitch L, Topolnytsky L. Affective, continuance, and normative commitment to the organization: A meta-analysis of antecedents, correlates, and consequences. J Vocat Behav. 2002; 61(1): 20-52. doi: 10.1006/jvbe.2001.1842.

22) Podsakoff PM, MacKenzie SB, Moorman RH, Fetter R. Transformational leader behaviors and their effects on followers' trust in leader, satisfaction, and organizational citizenship behaviors. The Leadership Quarterly. 1990; 1(2): 107-42. doi: 10.1016/1048-9843(90)90009-7.

23) Currall SC, Inkpen AC. A multilevel approach to trust in joint ventures. J Int Bus Stud. 2002; 33(3): 47995. doi: $10.1057 /$ palgrave.jibs.8491027.

24) Smith KG, Carroll SJ, Ashford SJ. Intra-and interorganizational cooperation: Toward a research agenda. Acad Manage J. 1995; 38(1): 7-23. doi: 10.2307/256726.

25) Settoon RP, Bennett N, Liden RC. Social exchange in organizations: Perceived organizational support, leader-member exchange, and employee reciprocity. J Appl Psychol. 1996; 81(3): 219. doi: 10.1037/00219010.81.3.219.

26) Ashja A, Nouri A, Arizi H, Samavatyan H. To Investigate The Rilationship of Personnel' s Percived Organization Justice and Trust (Organizational Trust and Trust in Supervisors). Knowledge and research in applied Psychology. 2009; 11(39): 1-12. 
27) Pillai R, Williams ES, Justin Tan J. Are the scales tipped in favor of procedural or distributive justice? An investigation of the US, India, Germany, and Hong Kong (China). J Confl Resolut. 2001; 12(4): 312-32. doi: 10.1108/eb022861.

28) Folger R, Konovsky MA. Effects of procedural and distributive justice on reactions to pay raise decisions. Acad Manage J. 1989; 32(1): 115-30. doi: 10.2307/256422.

29) DeConinck JB. The effect of organizational justice, perceived organizational support, and perceived supervisor support on marketing employees' level of trust. J Bus Res. 2010; 63(12): 1349-55. doi: 10.1016/j.jbusres.2010.01.003.

30) Wong Y-T, Ngo H-Y, Wong C-S. Perceived organizational justice, trust, and OCB: A study of Chinese workers in joint ventures and state-owned enterprises. J World Bus. 2006; 41(4): 344-55. doi: 10.1016/j.jwb.2006.08.003.

31) Gharaee H, Bahrami M, Rejaliyan F, Atashbahar O, Homayouni A, Ataollahi F. The relationship of organizational perceived justice and social responsibility in Yazd hospitals. Iran J Manage Med Inform Sch. 2013; 1(1): 26-37. PUB ID: 103-527-551.

32) Farndale E, Hope-Hailey V, Kelliher C. High commitment performance management: the roles of justice and trust. Personnel Review. 2011; 40(1): 5-23. doi: 10.1108/00483481111095492.

33) AL-Abrrow HA, Shaker Ardakani M, Harooni A. The relationship between organizational trust and organizational justice components and their role in job involvement in education. International Journal of Management Academy. 2013; 1(1): 25-41.

34) Karimi A, Alipour O, Pour MA, Azizi B. Relationship between organizational justice and job satisfaction in ministry of sports and youth in Iran. Int J Sport Stud. 2013; 3(11): 1149-56.

35) Bahrami MA, Montazeralfaraj R, Hashemi Gazar S, Dehghani Tafti A. Demographic determinants of organizational citizenship behavior among hospital employees. Glob Bus Manage Res: An Int J. 2013; 5(4): 171-8.

36) Iranzadeh S, Asadi N. The study of relationship of citizenship behavior and organizational justice with job happiness among the staff of Mohagheghe Ardabili university. Farasooye Modiriyat Journal. 2009; 3(10): 43-75.

37) Elovainio M, Kivimäki M, Steen N, Vahtera J. Job decision latitude, organizational justice and health: multilevel covariance structure analysis. Soc Sci Med. 2004; 58(9): 1659-69. doi: 10.1016/S02779536(03)00366.

38) Manzari TA, Rajabi M. The Relationship between Organizational Justice Perception and Job Satisfaction: a study on employees of Kerman University of Medical Sciences. Journal of health and development . 2013; 2(1): 22-32.

39) Ruder GJ. The relationship among organizational justice, trust, and role breadth self-efficacy: Virginia Polytechnic Institute and State University; Thesis of Ph.D. 2003: 112.

40) Moon H, Kamdar D, Mayer DM, Takeuchi R. Me or we? The role of personality and justice as othercentered antecedents to innovative citizenship behaviors within organizations. J Appl Psychol. 2008; 93(1): 84. doi: 10.1037/0021-9010.93.1.84.

41) De Cremer D, van Dijke M, Bos AE. Leader's procedural justice affecting identification and trust. Leadership Org Dev J. 2006; 27(7): 54-65. doi: 10.1108/01437730610692416. 